ADHD symptoms predict lower adaptation to the COVID-19 outbreak: financial decline, low adherence to preventive measures, psychological distress, and illness-related negative perceptions

Yehuda Pollak ${ }^{1},{ }^{*}$, Rachel Shoham ${ }^{2}$, Haym Dayan ${ }^{3}$, Ortal Gabrieli Seri ${ }^{1}$, Itai Berger ${ }^{3}$

${ }^{1}$ The Seymour Fox School of Education, The Hebrew University of Jerusalem, Jerusalem, Israel

${ }^{2}$ Special Education Department, Talpiot College, Holon, Israel

${ }^{3}$ The Paul Baerwald School of Social Work and Social Welfare, The Hebrew University of Jerusalem, Jerusalem, Israel 
Abstract

Objective. The COVID-19 outbreak created numerous multidimensional stressors, to which people show different levels of vulnerability. The current paper examines whether ADHD symptoms are associated with poorer adaptation.

Method. 2055 adults participated in an online survey after the first quarantine in Israel.

Participants completed scales probing adaptation indicators: financial status, adherence to preventive measures, mental health, and COVID-19 related perceptions. Background measures, including the level of ADHD symptoms, were collected.

Results. Adaptation indicators negatively correlated with the level of ADHD symptoms. Financial decline explained a small portion of the link between ADHD and decreased mental health; background risk-taking, anti-social, and pro-social behavior partially explained the link between ADHD and non-adherence to preventive measures; COVID-19 related perceptions also partially explained the same link.

Conclusion. The current study suggests that people with ADHD are more vulnerable to the challenges created by the COVID-19 pandemic and therefore deserve special attention and care.

Keywords: ADHD, COVID-19; Health; Well-Being; Pandemic 
The novel coronavirus 2019 (COVID-19) pandemic is a public health and global economy breakdown affecting every facet of society. At the individual level, the pandemic has created a myriad of long-term and multidimensional psychosocial stressors such as lockdown and social distancing, unemployment, as well as decreased family and social support that are important for financial security and emotion regulation (Gruber et al., 2020). As a result, deleterious effects on physical and mental health and life satisfaction are likely. International organizations advocate for integration of mental health and psychosocial support into the COVID-19 response (Moreno et al., 2020).

Different people will respond to the challenges of the pandemic by various behaviors and perceptions, thus demonstrating variable degree of adaptation. Vulnerable people might be at increased risk and are expected to show lower levels of adaptation. Indeed, a recent study demonstrated substantial increases in distress during the emergence of the COVID-19 crisis. Importantly, those with pre-existing mental health conditions were more likely to show a rise in distress (Daly \& Robinson, 2020).

Attention deficit/hyperactivity disorder (ADHD) is a neurodevelopmental condition characterized by inattention, hyperactivity, and impulsivity leading to functional impairment (American Psychiatric Association, 2013). ADHD is one of the earliest reliable predictors of long term poor health outcomes, including various psychiatric and physical disorders, smoking and substance use, risky behavior, and accidental injury (Nigg, 2013). Being a risk factor for multiple adverse outcomes, ADHD might confer increased vulnerability to significant life transitions and challenges such as recently presented by the COVID-19 pandemic.

Tremendous changes in life are not uncommon. An onset of a health condition, transition to college life, grief after a loss of a beloved person, etc., all demand adaptation of psycho-behavioral 
functions. Adaptability, the capacity to constructively adapt to new or changing situations, relates to behavioral, cognitive and emotional regulation (Martin, Nejad, Colmar, \& Liem, 2012). Individuals who are deficient in regulatory functions might show vulnerability to higher stress in times of change. The literature has long documented lower regulatory skills in ADHD (Barkley, 1997) showing more difficulties to manage increased stress levels (Hirvikoski et al., 2011; Lackschewitz, Hüther, \& Kröner-Herwig, 2008). In the face of stressful episodes, individuals with ADHD more frequently use maladaptive coping strategies such as escape-avoidance, confrontational, and unplanned problem-solving (Hampel, Manhal, Roos, \& Desman, 2008; Oster, Ramklint, Meyer, \& Isaksson, 2019; Young, 2005). Individuals with ADHD reported greater stress in transition to college, demonstrating unhealthy coping skills and lower adaptability (Martin, \& Burns, 2014). In transition to military service in countries like Korea, Singapore and the US, individuals with ADHD experience higher emotional distress, more alcohol and caffeine use, and reduced quality of life (Cipollone et al., 2020; Noh, Lee, \& Bahn, 2018). Finally, the high prevalence of ADHD among patients with post-traumatic stress disorder (PTSD) suggests that ADHD is a vulnerability factor for developing PTSD following an exposure to stress (Adler, Kunz, Chua, Rotrosen, \& Resnick, 2004).

In line with the suggestion that ADHD is a vulnerability factor to adaptation, the present study aimed to examine the links between ADHD and adaptation indicators during the COVID-19 outbreak. Specifically, the links between ADHD symptoms and financial decline, adherence to preventive measures, psychological distress and life satisfaction, as well as to COVID-19 related perceptions, were examined.

Methods 
Data from a study that aimed to detect risk factors for non-adherence to preventive measures was re-analyzed for the purpose of the current research. The methods of the study have been described extensively in the manuscript summarizing the primary findings of the study (Pollak, Shoham, Dayan, Gabrieli Seri, \& Berger, MedRxiv). Below are only methods that were used for the current paper, briefly described.

The study was approved by the ethics committee of the Seymour Fox School of Education at the Hebrew University of Jerusalem. From May 13 to 23, 2020, a sample of 2055 online panel respondents was recruited (https://www.panel4all.co.il) representing the variety of the adult Israeli population.

\section{Outcome measures}

For the current study, the main outcome variables were financial decline, low adherence to preventive measures, psychological distress, and illness-related perceptions. Financial decline was measured by a five-point question concerning the level of decrease in income since the onset of the outbreak $(1=$ no decrease at all, $5=$ a sharp decrease $)$. In addition, Participants reported their pre-outbreak and current percent of position. A difference score was computed and categorized into a binary variable $(0=$ no decrease, $1=$ decrease $)$. Low adherence to preventive measures was probed by a 13-item questionnaire. Participants rated the extent of which they adhered to each of 13 preventive measures that were released by the Israeli Ministry of Health at the corresponding period (focusing on social distancing, personal hygiene practicing, facemask wearing) on a five-point Likert scale $(1=$ not at all, $5=$ strictly $)$. Psychological distress was measures by the Kessler Screening Scale (K6) probing current non-specific psychiatric symptoms (Kessler et al., 2002). Life satisfaction was probed by two questions concerning the current level of happiness and satisfaction from life. COVID-19-related perception measures 
included the perceived risk of COVID-19, the perceived efficacy of the preventive measures, the perceived costs of adherence to preventive measures, and the perceived norms regarding adherence to preventive measures (see Pollak et al. MedRxiv for detailed description of the measures).

The independent variable, level of ADHD symptoms, was measured by the Hebrew version of the Adult ADHD Self-Report Scale for measuring the level of ADHD symptoms (Kessler et al., 2005).

Other background measures consisted of sociodemographic, behavioral, and personality characteristics. Sociodemographic measures included age, gender, marital status, having children, religiousness, education, place of living (urban versus rural), background migration, and pre-outbreak level of income. In addition, participants reported whether they were confirmed COVID-19 cases. Behavioral and personality measures included a short form of the Adult RiskTaking Inventory (ARTI) (Shoham, Sonuga-Barke, Yaniv, \& Pollak, 2019, 2020), past antisocial behavior scale (adapted from Cho, Martin, Conger, \& Widaman, 2010), and the pro-social subscale of the young adult Strengths and Difficulties Questionnaire (Brann, Lethbridge, \& Mildred, 2018).

Statistical analysis

Descriptive statistics included medians and ranges of the continuous variables and frequency and percentage of categorical variables. Spearman correlations were used to measure the links between the ASRS score and the different adaptation indicator. Linear regression analyses were used to covariate for demographic variables (gender, age, religiousness, marital status) and for examining the specific contributions of ADHD symptoms clusters (inattention, 
hyperactivity/impulsivity) to the prediction of the continuous outcome measures. The direct and indirect effects of ADHD symptoms on the outcome measures through financial decline, behavioral characteristics, and COVID-19-related perceptions were calculated using the multiple mediation approach and the SPSS macro (PROCESS, Model 6) provided by Hayes (2017). The significance of the indirect effects was tested via a commonly performed bootstrap analysis (bias-corrected and accelerated, 5000 samples), which allows for greater statistical power in multiple mediator analyses. All analyses were conducted using SPSS 25.0, including an SPSS macro designed for assessing multiple mediation models (Preacher \& Hayes, 2008).

Results

Descriptive statistics

Table 1 present the sociodemographic, clinical, and behavioral characteristics and COVID-19 perceptions of the sample.

Table 1: Demographic and clinical characteristics

Categorical variables

Gender

Females

Males

Religiosity

Non-religious

Religious

$\mathrm{n} \quad \%$

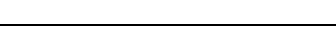

$1128 \quad 55.4 \%$

$909 \quad 44.6 \%$

$1501 \quad 73.7 \%$

$535 \quad 26.3 \%$ 


\section{Marital status}

Not married

$740 \quad 36.2 \%$

Married

$1302 \quad 63.8 \%$

Having children

No children

$582 \quad 31.7 \%$

Children

$1253 \quad 68.3 \%$

Higher education

No

$983 \quad 48.3 \%$

Yes

$1054 \quad 51.7 \%$

Pre-outbreak level of income

Much more than average

$78 \quad 3.8 \%$

More than average

$292 \quad 14.3 \%$

Average

$611 \quad 30.0 \%$

Less more than average

$498 \quad 24.4 \%$

Much less than average

$561 \quad 27.5 \%$

Decrease in percent of position

No

$1231 \quad 62.8 \%$

Yes

$729 \quad 37.2 \%$

Continuous variables

$M d n \quad(25 \%-75 \%)$

Age

$37.0 \quad(27.00-52.00)$

Decline in income (1-5 scale)

$2.00 \quad(1.00-4.00)$

Adherence to preventive measures (1-5 scale)

$4.15 \quad(3.62-4.62)$ 


\section{Mental health measures}

Life satisfaction

$3.00 \quad(2.00-3.00)$

Psychological Distress (K6)

$1.83 \quad(1.50-2.50)$

\section{Behavioral and personality}

ARTI

Antisocial

Prosocial

COVID-19-related perception measures

Norm

$4.00 \quad(3.25-4.50)$

Cost

2.71

$(2.14-3.43)$

Risk

$3.00 \quad(2.64-3.45)$
ADHD symptoms - mean ASRS score (1-5 scale)
Total
Inattention
Hyperactivity
$2.17(1.78-2.56)$
$2.22 \quad(1.78-2.67)$
$2.11 \quad(1.67-2.56)$

Note: $\mathrm{ADHD}=$ attention deficit/hyperactive disorder, Antisocial $=$ past anti-social behavior, ARTI $=$ a short form of the Adult Risk-Taking Inventory, ASRS = the Hebrew version of the Adult ADHD Self-Report Scale, Cost $=$ the perceived costs of adherence to preventive measures, Efficacy $=$ the perceived efficacy of the preventive measures, Norm $=$ the perceived norms regarding adherence to preventive measures, Prosocial = pro-social subscale of the young adult Strengths and Difficulties Questionnaire (SDQ), Psychological Distress (K6) = Kessler Screening Scale for Psychological Distress, Risk = perceived risk of COVID-19. 
Table 2 presents the correlations between level of ADHD symptoms and each of the adaption indicators. ADHD symptoms correlated with all outcome variables. A set of regression analyses included all demographic variables in the first block and the intention and hyperactivity/impulsivity subscales scores of ASRS in the second block. The second block remained a significant predictor of all outcome variables above and beyond the demographic variables. Inattention symptoms predicted decrease in income above and beyond hyperactivity symptoms, but not vice versa. Hyperactivity/impulsivity symptoms predicted increase in perceived risk and decrease in perceived efficacy above and beyond inattention symptoms, but not vice versa. Both inattention and hyperactivity predicted mental health outcome (K6 and life satisfaction scores), adherence to preventive measures, and perceived norms and costs of adherence to preventive measures above and beyond each other (see Table S1-2 in the Supplementary Materials). 
Table 2: Spearman's rho correlations between ADHD symptoms and outcome variables

\begin{tabular}{lcccc}
\hline ADHD symptoms & Finance & $\begin{array}{c}\text { Mental health } \\
\text { measures }\end{array}$ & $\begin{array}{c}\text { Behavioral and personality } \\
\text { COVID-19-related perception measures }\end{array}$ & $\begin{array}{c}\text { Adherence to } \\
\text { preventive } \\
\text { measures }\end{array}$ \\
\hline
\end{tabular}

\section{ADHD symptoms}

Mean ASRS

2 Inattention

3 Hyperactivity

$.913^{* *} \quad-$

$.912 * * \quad .679 * * \quad-$

\section{Finance}

Decrease in i

5 Decrease in percent of position

\section{Mental health measures}

6 Psychological Distress (K6)

7 Life satisfaction

\section{Behavioral and personality}

Prosocial

9 Antisocial

10 ARTI

\section{COVID-19-related perception}

\section{measures}

11 Risk

12 Efficacy

13 Cost

14 Norm

15 Adherence to preventive

$\begin{array}{llll}.135^{* *} & .127^{* *} & .120^{* *} & - \\ .110^{* *} & .107^{* *} & .094^{* *} & .608^{* *}\end{array}$

$\begin{array}{lllll}.535^{* *} & .468^{* *} \quad .519^{* *} \quad .214^{* *} \quad .154 * * \quad-\end{array}$

$\begin{array}{llllll}-.309 * * & -.299 * * & -.274 * * & -.160 * * & -.125 * * & -.569 * *\end{array}$

$\begin{array}{llllllll}-.098 * * & -.095 * * & -.082 * * & .015 & .008 & -.102 * * & -.201 * * & -\end{array}$

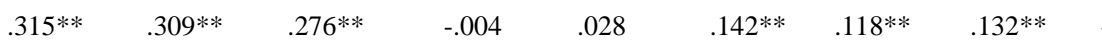

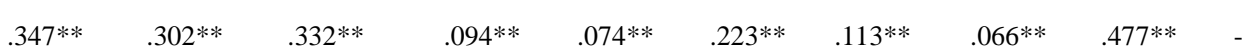

\section{measures}

Note: ADHD = attention deficit/hyperactive disorder, ARTI = a short form of the Adult Risk-Taking Inventory, ASRS = the Hebrew version of the Adult ADHD Self-Report

Scale, Cost $=$ the perceived costs of adherence to preventive measures, Decrease in income $=$ decrease in income since the onset of the outbreak, Decrease in percent of position $=$ 
pre-outbreak level of income, Efficacy = the perceived efficacy of the preventive measures, Norm = the perceived norms regarding adherence to preventive measures, Psychological Distress K6 = Kessler Screening Scale for Psychological Distress, Risk = perceived risk of COVID-19, 
In an additional set of analyses, indirect pathways between ADHD symptoms and different outcome variable were examined (see Table 3). The first two mediation models examined whether the link between ADHD symptoms and decrease in income explains the increase in psychological distress and decrease in life satisfaction. The first model demonstrated a small but significant indirect pathway between the ASRS and K6 scores through the level of decrease in income. In a similar vein, the second model revealed a small but significant indirect pathway between the ASRS and life satisfaction scores through the level of decrease in income. The next models examined indirect pathways between ADHD symptoms and lower adherence to preventive measures. The third model revealed significant indirect pathways between the ASRS and lower adherence to preventive measures through increased risk-taking behavior and antisocial behavior and decreased prosocial behavior. The fourth model revealed significant indirect pathways between the ASRS and lower adherence to preventive measures through increased perceived non-adherence norms to the preventive measures and increased perceived cost of the preventive measures. Also, a significant indirect pathway through decreased perceived efficacy of the preventive measures was found. On the other hand, an indirect pathway through increased perceived risk of the COVID-19 illness diminished the negative link between ADHD and adherence. Interestingly, adding K6 as a covariate to the model reduced the indirect pathway through the perceived risk (see Table 3). 
Table 3: Mediation coefficients and confidence intervals (CIs)

\begin{tabular}{|c|c|c|c|c|c|c|}
\hline \multirow{3}{*}{$\begin{array}{l}\begin{array}{l}\text { Dependent } \\
\text { Variable }\end{array} \\
\text { K6 }\end{array}$} & \multirow{3}{*}{$\begin{array}{l}\text { Model R }{ }^{2} \\
31.33\end{array}$} & \multicolumn{4}{|c|}{ Indirect effect: } & \multirow{3}{*}{$\begin{array}{c}\text { Direct effect } \\
\\
\text { 0.469 } \\
95 \% \text { CI }[0.428,0.509]\end{array}$} \\
\hline & & \multicolumn{4}{|l|}{ Decrease in income } & \\
\hline & & \multicolumn{4}{|l|}{$\begin{array}{c}0.015 \\
95 \% \text { CI }[0.007,0.024]\end{array}$} & \\
\hline \multirow{4}{*}{ Life satisfaction } & \multirow{3}{*}{16.09} & \multicolumn{5}{|l|}{ Decrease in income } \\
\hline & & $\begin{array}{c}-0.013 \\
95 \% \text { CI }[-0.06,-0.022]\end{array}$ & & & & \multirow[t]{3}{*}{$\begin{array}{c}-0.301 \\
95 \% \text { CI }[-0.257,-0.346]\end{array}$} \\
\hline & & \multicolumn{3}{|l|}{ Behavioral and personality } & & \\
\hline & & ARTI & Antisocial & Prosocial & & \\
\hline \multirow{3}{*}{$\begin{array}{l}\text { Adherence to } \\
\text { preventive } \\
\text { measures }\end{array}$} & 16.74 & $\begin{array}{c}-0.036 \\
95 \% \text { CI }[-0.054,-0.021]\end{array}$ & $\begin{array}{c}-0.057 \\
95 \% \text { CI }[-0.075,-0.038]\end{array}$ & $\begin{array}{c}-0.007 \\
95 \% \text { CI [-0.014, }-\mathbf{0 . 0 0 1 ]}\end{array}$ & & \multirow[t]{3}{*}{$\begin{array}{c}-0.088 \\
95 \% \text { CI }[-0.134,-0.041]\end{array}$} \\
\hline & & \multicolumn{4}{|c|}{ COVID-19-related perception measures } & \\
\hline & & Norm & Cost & Risk & Efficacy & \\
\hline \multirow{3}{*}{$\begin{array}{l}\text { Adherence to } \\
\text { preventive } \\
\text { measures }\end{array}$} & 29.34 & $\begin{array}{c}-0.030 \\
95 \% \text { CI }[-0.045,-0.018]\end{array}$ & $\begin{array}{c}-0.017 \\
95 \% \text { CI [-0.031, }-0.004]\end{array}$ & $\begin{array}{c}0.035 \\
95 \% \text { CI }[0.021,0.050]\end{array}$ & $\begin{array}{c}-0.037 \\
95 \% \text { CI }[-0.053,-0.022]\end{array}$ & $\begin{array}{c}-0.140 \\
95 \% \text { CI }[-0.184,-0.096]\end{array}$ \\
\hline & & \multicolumn{4}{|c|}{ COVID-19-related perception measures with Psychological Distress (K6) covariated } & \\
\hline & & Norm & Cost & Risk & Efficacy & \\
\hline $\begin{array}{l}\text { Adherence to } \\
\text { preventive } \\
\text { measures }\end{array}$ & 29.34 & $\begin{array}{c}-0.026 \\
95 \% \text { CI }[-0.041,-0.014]\end{array}$ & $\begin{array}{c}-0.010 \\
95 \% \text { CI }[-0.019,-0.002]\end{array}$ & $\begin{array}{c}0.014 \\
95 \% \text { CI [-0.000, 0.029] }\end{array}$ & $\begin{array}{c}-0.031 \\
95 \% \text { CI }[-0.048,-0.015]\end{array}$ & $\begin{array}{c}-0.141 \\
95 \% \text { CI [-0.189, }-0.093]\end{array}$ \\
\hline
\end{tabular}

Final mediation path analysis predicting adherence to preventive measures. The values shown are the standardized regression coefficients of the indirect and direct effects (taking into account other mediators) of ADHD symptoms upon adherence to preventive measures. In bold are the variables that were significant (the respective $95 \%$ bias-corrected confidence intervals did not contain zero in bootstrap analyses). The covariates of age, gender, marital status, child, religious, higher education and income are not shown in the table for the sake of brevity. 


\section{Discussion}

The current paper examined the link between ADHD symptoms and adaptation indicators to the COVID-19 pandemic in several domains. It was found that higher levels of ADHD symptoms predicted lower economic outcome, mental health indices, and adherence to preventive measures. In addition, ADHD symptoms correlated with higher perceived risk of COVID-19 but also with perceptions that encourage non-adherence to preventive measures.

ADHD symptoms predict financial decline

Level of ADHD symptoms correlated with a decrease in percent of position and in income. Furthermore, this correlation explained a small but significant proportion of the variance in the link between ADHD and psychological distress. Inattention rather than hyperactivity/impulsivity symptoms predicted financial decline, in line with a study reporting that persisting high levels of ADHD inattention symptoms in adulthood predicted occupational outcome (Fredriksen et al., 2014; Gjervan, Torgersen, Nordahl, \& Rasmussen, 2012). Interestingly, economic decline correlated with COVID-19 related perceptions, such that participants who experienced greater financial problems perceived the illness as more severe and the preventive measures as more costly and less effective.

ADHD symptoms predict lower adherence to preventive measures

Level of ADHD symptoms correlated with lower level of adherence to preventive measures. Non-adherence to preventive measures reflects risk-taking behavior as it increases the likelihood of infection. Indeed, ADHD was found to be a risk factor for COVID-19 infection (Merzon et al., 2020). Also, as the preventive measures were mandatory in Israel at the time of the study, nonadherence may also be considered as anti-social behavior. Importantly, both risk-taking and anti- 
social behavior are closely related to ADHD (Pollak, Dekkers, Shoham, \& Huizenga, 2019; Retz et al., 2020). Accordingly, the link between ADHD and non-adherence was partially explained by high levels of risk-taking and anti-social behavior.

Non-adherence to preventive measures correlated with illness-related perceptions, namely, with lower perceived severity of the illness, lower perceived efficacy of and lower perceived norms of adhering to the preventive measures, and higher perceived cost of adherence. In our sample, level of ADHD symptoms correlated with lower perceived efficacy and norms and with higher perceived cost of adherence to the preventive measures, explaining part of the link between ADHD and non-adherence. On the other hand, levels of ADHD symptoms also correlated with higher perceived illness severity, tempering the tendency toward non-adherence. Interestingly, the link between ADHD and perceived illness severity was fully nullified by controlling for psychological distress, suggesting a common source for ADHD-related increase in perceived illness severity and psychological distress.

ADHD symptoms predict higher psychological distress

Level of ADHD symptoms also predicted higher psychological distress and lower life satisfaction. Notably, these links are not unique to the COVID-19 outbreak era (APA, 2013). Therefore, the findings may indicate that during the period of the study people with high levels of ADHD symptoms were more likely to experience distress, but not necessarily that these people experienced more distress than they had experienced before the outbreak. Importantly, part of the link between ADHD and psychological distress was accounted for by financial decline, suggesting that at least some of the negative consequences of the pandemic aggravated pre-outbreak levels of distress of people with high levels of ADHD symptoms. 
The study has limitations. ADHD was dimensionally defined and did not focus on a comparison between people who meet the DSM-5 criteria of ADHD. All measures were based on self-report and not on objective observations. Data collection took place at relatively early stages of the pandemic and might not be fully generalizable to later stages.

\section{Clinical implications}

The COVID-19 outbreak's deleterious effects on the individual's financial security and health are well recognized, and international organizations advocate for integration of mental health and psychosocial support into the COVID-19 response (Moreno et al., 2020). The current study suggests that people with ADHD are even more vulnerable to the challenges created by the COVID-19 pandemic and therefore deserve special attention and care. Specifically, vocational, and mental counseling is important, as well as fostering healthy lifestyle that includes optimal adherence to preventive measures.

The documented vulnerability among people with ADHD to the challenges of the COVID-19 pandemic is a matter of concern since it leads them to undesirable consequences. This study highlights the difficulty of people with ADHD to adopt a new lifestyle of preventive measures and offers new insights into this tendency. In treating people with ADHD who show adaptation problems, clinicians should attend to the ways their patients view the positive outcomes of nonadherence and the perceived low efficacy of the adherence, rather than how they assess the potential risks of the illness. Therapeutic discourse could thus focus on the benefits attained from non-adherence, in attempt to help patients develop more adaptive decision-making skills. 
References

Adler, L. A., Kunz, M., Chua, H. C., Rotrosen, J., \& Resnick, S. G. (2004). Attentiondeficit/hyperactivity disorder in adult patients with posttraumatic stress disorder (PTSD): is ADHD a vulnerability factor? J Atten Disord, 8(1), 11-16.

doi:10.1177/108705470400800102

American Psychiatric Association. (2013). Diagnostic and Statistical Manual of Mental Disorders (5th Ed.). Washington, DC

Barkley, R. A. (1997). Attention-deficit/hyperactivity disorder, self-regulation, and time: toward a more comprehensive theory. J Dev Behav Pediatr, 18(4), 271-279.

Brann, P., Lethbridge, M. J., \& Mildred, H. (2018). The young adult Strengths and Difficulties Questionnaire (SDQ) in routine clinical practice. Psychiatry Res, 264, 340-345. doi:10.1016/j.psychres.2018.03.001

Cho, Y. I., Martin, M. J., Conger, R. D., \& Widaman, K. F. (2010). Differential Item Functioning on Antisocial Behavior Scale Items for Adolescents and Young Adults from SingleParent and Two-Parent Families. J Psychopathol Behav Assess, 32(2), 157-168. doi:10.1007/s10862-009-9145-1

Cipollone, G., Gehrman, P., Manni, C., Pallucchini, A., Maremmani, A. G. I., Palagini, L., .. . Maremmani, I. (2020). Exploring the Role of Caffeine Use in Adult-ADHD Symptom Severity of US Army Soldiers. J Clin Med, 9(11). doi:10.3390/jcm9113788

Daly, M., \& Robinson, E. (2020). Psychological distress and adaptation to the COVID-19 crisis in the United States. J Psychiatr Res. doi:10.1016/j.jpsychires.2020.10.035

Fredriksen, M., Dahl, A. A., Martinsen, E. W., Klungsoyr, O., Faraone, S. V., \& Peleikis, D. E. (2014). Childhood and persistent ADHD symptoms associated with educational failure 
and long-term occupational disability in adult ADHD. ADHD Attention Deficit and Hyperactivity Disorders, 6(2), 87-99. doi:10.1007/s12402-014-0126-1

Gjervan, B., Torgersen, T., Nordahl, H. M., \& Rasmussen, K. (2012). Functional Impairment and Occupational Outcome in Adults With ADHD. Journal of Attention Disorders, 16(7), 544-552. doi:10.1177/1087054711413074

Gruber, J., Prinstein, M. J., Clark, L. A., Rottenberg, J., Abramowitz, J. S., Albano, A. M., . . Weinstock, L. M. (2020). Mental health and clinical psychological science in the time of COVID-19: Challenges, opportunities, and a call to action. Am Psychol. doi:10.1037/amp0000707

Hampel, P., Manhal, S., Roos, T., \& Desman, C. (2008). Interpersonal coping among boys with ADHD. J Atten Disord, 11(4), 427-436. doi:10.1177/1087054707299337

Hayes, A. F. (2017). Introduction to mediation, moderation, and conditional process analysis: A regression-based approach . (2nd ed.): Guilford publications.

Hirvikoski, T., Olsson, E. M., Nordenstrom, A., Lindholm, T., Nordstrom, A. L., \& Lajic, S. (2011). Deficient cardiovascular stress reactivity predicts poor executive functions in adults with attention-deficit/hyperactivity disorder. J Clin Exp Neuropsychol, 33(1), 6373. doi:10.1080/13803395.2010.493145

Kessler, R. C., Adler, L., Ames, M., Demler, O., Faraone, S., Hiripi, E., ... Walters, E. E. (2005). The World Health Organization Adult ADHD Self-Report Scale (ASRS): a short screening scale for use in the general population. Psychol Med, 35(2), 245-256. doi: $10.1017 / \mathrm{s} 0033291704002892$

Kessler, R. C., Andrews, G., Colpe, L. J., Hiripi, E., Mroczek, D. K., Normand, S. L., . . . Zaslavsky, A. M. (2002). Short screening scales to monitor population prevalences and 
trends in non-specific psychological distress. Psychol Med, 32(6), 959-976. doi: $10.1017 / \mathrm{s} 0033291702006074$

Lackschewitz, H., Hüther, G., \& Kröner-Herwig, B. (2008). Physiological and psychological stress responses in adults with attention-deficit/hyperactivity disorder (ADHD). Psychoneuroendocrinology, 33(5), 612-624. doi:10.1016/j.psyneuen.2008.01.016

Martin, A. J., \& Burns, E. C. (2014). Academic Buoyancy, Resilience, and Adaptability in Students with ADHD. The ADHD Report, 22, 1-9.

Martin, A. J., Nejad, H., Colmar, S., \& Liem, G. A. D. (2012). Adaptability: Conceptual and empirical perspectives on responses to change, novelty and uncertainty. . Australian Journal of Guidance and Counselling, 22, 58-81.

Merzon, E., Manor, I., Rotem, A., Schneider, T., Vinker, S., Golan Cohen, A., . . . Green, I. (2020). ADHD as a Risk Factor for Infection With Covid-19. J Atten Disord, 1087054720943271. doi:10.1177/1087054720943271

Moreno, C., Wykes, T., Galderisi, S., Nordentoft, M., Crossley, N., Jones, N., . . Arango, C. (2020). How mental health care should change as a consequence of the COVID-19 pandemic. Lancet Psychiatry, 7(9), 813-824. doi:10.1016/S2215-0366(20)30307-2

Nigg, J. T. (2013). Attention-deficit/hyperactivity disorder and adverse health outcomes. Clin Psychol Rev, 33(2), 215-228. doi:10.1016/j.cpr.2012.11.005

Noh, G. M., Lee, S. M., \& Bahn, G. H. (2018). Social function of adult men with attentiondeficit/hyperactivity disorder in the context of military service. Neuropsychiatr Dis Treat, 14, 3349-3354. doi:10.2147/NDT.S180806 
Oster, C., Ramklint, M., Meyer, J., \& Isaksson, J. (2019). How do adolescents with ADHD perceive and experience stress? An interview study. Nord J Psychiatry, 1-8. doi:10.1080/08039488.2019.1677771

Pollak, Y., Dekkers, T. J., Shoham, R., \& Huizenga, H. M. (2019). Risk-Taking Behavior in Attention Deficit/Hyperactivity Disorder (ADHD): a Review of Potential Underlying Mechanisms and of Interventions. Curr Psychiatry Rep, 21(5), 33. doi:10.1007/s11920019-1019-y

Preacher, K. J., \& Hayes, A. F. (2008). Asymptotic and resampling strategies for assessing and comparing indirect effects in multiple mediator models. Behavior Research Methods, 40(3), 879-891. doi:10.3758/brm.40.3.879

Retz, W., Ginsberg, Y., Turner, D., Barra, S., Retz-Junginger, P., Larsson, H., \& Asherson, P. (2020). Attention-Deficit/Hyperactivity Disorder (ADHD), antisociality and delinquent behavior over the lifespan. Neurosci Biobehav Rev. doi:10.1016/j.neubiorev.2020.11.025

Shoham, R., Sonuga-Barke, E., Yaniv, I., \& Pollak, Y. (2019). ADHD Is Associated With a Widespread Pattern of Risky Behavior Across Activity Domains. J Atten Disord, 1087054719875786. doi:10.1177/1087054719875786

Shoham, R., Sonuga-Barke, E., Yaniv, I., \& Pollak, Y. (2020). What Drives Risky Behavior in ADHD: Insensitivity to its Risk or Fascination with its Potential Benefits? J Atten Disord, 1087054720950820. doi:10.1177/1087054720950820

Young, S. (2005). Coping strategies used by adults with ADHD. . Personality and Individual Differences, 38, 809-816. 


\section{Supplementary Materials:}

Table S1. Prediction of Financial Decline, Adherence to Preventive Measures, Psychological Distress, Life Satisfaction, and COVID-19 Related Perceptions by Demographics and ADHD Symptoms

\begin{tabular}{|c|c|c|c|c|c|c|c|c|c|c|c|c|c|c|c|c|}
\hline \multirow{2}{*}{ Predictor } & \multicolumn{3}{|c|}{ Financial Decline } & \multirow[b]{2}{*}{$\beta$} & \multicolumn{4}{|c|}{ Adherence to Preventive Measures } & \multicolumn{4}{|c|}{ Psychological Distress } & \multicolumn{4}{|c|}{ Life Satisfaction } \\
\hline & $\Delta R^{2}$ & $B$ & $95 \% \mathrm{Cl}$ & & $\Delta R^{2}$ & $B$ & $95 \% \mathrm{Cl}$ & $\beta$ & $\Delta R^{2}$ & $B$ & $95 \% \mathrm{Cl}$ & $\beta$ & $\Delta R^{2}$ & $B$ & $95 \% \mathrm{Cl}$ & $\beta$ \\
\hline Block 1 & $.034^{*}$ & & & & $.050^{*}$ & & & & $.070^{*}$ & & & & $.055^{*}$ & & & \\
\hline Age & & -.012 & $-.017--.006$ & -.117 & & .008 & $.006-.011$ & .171 & & -.009 & $-.012--.006$ & -.173 & & -.004 & $-.007--.001$ & -.082 \\
\hline Gender & & .031 & $-.118-.184$ & .010 & & .153 & $.082-.224$ & .103 & & .176 & . $101-.254$ & .110 & & -.084 & $-.154--.014$ & -.059 \\
\hline Marital Status & & .046 & $-.150-.241$ & .014 & & .072 & $-.016-.162$ & .046 & & .007 & $-.094-.107$ & .004 & & .180 & $.094-.268$ & .120 \\
\hline Having Children & & .092 & $-.140-.320$ & .029 & & .031 & $-.067-.129$ & .020 & & -.078 & $-.209-.051$ & -.046 & & .071 & $-.029-.171$ & .047 \\
\hline Religious & & $\begin{array}{l}.156 \\
\end{array}$ & $-.315--.003$ & -.046 & & .013 & $-.063-.093$ & .008 & & -.140 & $-.221--.052$ & -.077 & & .214 & $.139-.287$ & .133 \\
\hline Income & & -.157 & $-.223--.092$ & -.120 & & -.031 & $-.064-.000$ & -.049 & & -.052 & $-.088--.016$ & -.075 & & .040 & $.010-.071$ & .066 \\
\hline Block 2 & $.012^{*}$ & & & & $.035 *$ & & & & $.229 *$ & & & & .096* & & & \\
\hline Age & & -.010 & $-.016--.005$ & -.100 & & .007 & $.004-.010$ & .141 & & -.005 & $-.008--.002$ & -.093 & & -.006 & $-.009--.004$ & -.132 \\
\hline Gender & & .024 & $-.129-.177$ & .008 & & .159 & $.087-.228$ & .107 & & .145 & $.079-.211$ & .090 & & -.076 & $-.144--.008$ & -.053 \\
\hline Marital Status & & .055 & $-.140-.248$ & .017 & & .063 & $-.023-.150$ & .041 & & .032 & $-.056-.119$ & .019 & & .168 & $.086-.247$ & .112 \\
\hline Having Children & & .105 & $-.125-.326$ & .032 & & .022 & $-.075-.122$ & .014 & & -.049 & $-.158-.052$ & -.029 & & .054 & $-.041-.150$ & .036 \\
\hline Religious & & -.158 & $-.316-. .006$ & -.046 & & .014 & $-.062-.094$ & .008 & & -.143 & $-.215--.067$ & -.079 & & .215 & $.143-.286$ & .134 \\
\hline Higher Education & & $\begin{array}{l}-.114 \\
\end{array}$ & $-.261-.031$ & -.038 & & .006 & $-.065-.078$ & .004 & & .007 & $-.059-.074$ & .004 & & .015 & $-.049-.081$ & .011 \\
\hline Inattention & & .183 & $.018-.349$ & .079 & & -.153 & $-.225--.082$ & -.136 & & .205 & $.127-.283$ & .168 & & -.242 & $-.313--.170$ & -.224 \\
\hline Hyperactivity & & .091 & $-.074-.252$ & .039 & & -.078 & $-.151--.004$ & -.069 & & .440 & $.359-.520$ & .358 & & -.127 & $-.201--.052$ & -.117 \\
\hline
\end{tabular}




\begin{tabular}{|c|c|c|c|c|c|c|c|c|c|c|c|c|c|c|c|c|}
\hline \multirow{2}{*}{ Predictor } & \multicolumn{3}{|c|}{ Perceived Risk } & \multirow[b]{2}{*}{$\beta$} & \multicolumn{4}{|c|}{ Perceived Norms } & \multicolumn{4}{|c|}{ Perceived Efficacy } & \multicolumn{4}{|c|}{ Perceived Cost } \\
\hline & $\Delta R^{2}$ & $B$ & $95 \% \mathrm{Cl}$ & & $\Delta R^{2}$ & $B$ & $95 \% \mathrm{Cl}$ & $\beta$ & $\Delta R^{2}$ & $B$ & $95 \% \mathrm{Cl}$ & $\beta$ & $\Delta R^{2}$ & $B$ & $95 \% \mathrm{Cl}$ & $\beta$ \\
\hline Block 1 & $.049 *$ & & & & $.042 *$ & & & & $.040 *$ & & & & $.020^{*}$ & & & \\
\hline Age & & .005 & \begin{tabular}{|l|}
$.003-.007$ \\
\end{tabular} & .117 & & .008 & $.005-.011$ & .153 & & .009 & $.006-.012$ & .154 & & -.007 & $-.010--.003$ & -.107 \\
\hline Gender & & .140 & .079-.199 & .112 & & .128 & $.050-.209$ & \begin{tabular}{|l|}
.078 \\
\end{tabular} & & .105 & $.024-.183$ & .062 & & -.034 & $-.122-.051$ & -.018 \\
\hline Marital Status & & \begin{tabular}{|l|}
.097 \\
\end{tabular} & $.020-.174$ & .074 & & .008 & \begin{tabular}{|l|}
$-.088-.103$ \\
\end{tabular} & \begin{tabular}{|l|}
.005 \\
\end{tabular} & & .058 & $-.049-.166$ & .032 & & -.008 & $-.133-.117$ & -.004 \\
\hline Having Children & & .013 & $-.075-.105$ & .010 & & .012 & $-.103-.131$ & \begin{tabular}{|l|}
.007 \\
\end{tabular} & & .020 & $-.101-.149$ & .011 & & .003 & $-.137-.150$ & .002 \\
\hline Religious & & -.116 & $-. .183--.051$ & -.083 & & .190 & $.104-.277$ & .102 & & .103 & $.011-.191$ & .054 & & -.035 & $-.131-.064$ & -.017 \\
\hline Income & & -.054 & $-.081--.026$ & -.100 & & -.005 & \begin{tabular}{|l|}
$-.045-.032$ \\
\end{tabular} & \begin{tabular}{|l|}
$.007-$ \\
\end{tabular} & & -.018 & $-.056-.019$ & -.025 & & -.040 & $-.083-.001$ & -.050 \\
\hline Block 2 & $.019 *$ & & & & $.035^{*}$ & & & & $.026 *$ & & & & $.077^{*}$ & & & \\
\hline Age & & .006 & $.003-.008$ & .140 & & .007 & $.004-.010$ & .123 & & .007 & $.004-.010$ & .128 & & -.004 & $-.007-.000$ & -.062 \\
\hline Gender & & .134 & $.074-.193$ & .108 & & .135 & $.058-.214$ & \begin{tabular}{|l|}
.082 \\
\end{tabular} & & .114 & $.035-.189$ & .067 & & -.053 & $-.139-.029$ & -.029 \\
\hline Marital Status & & .103 & $.027-.178$ & .078 & & -.001 & \begin{tabular}{|l|}
$.096-.092$ \\
\end{tabular} & \begin{tabular}{|l|}
.000 \\
\end{tabular} & & .049 & $-.054-.153$ & .027 & & .010 & $-.107-.131$ & .005 \\
\hline Having Children & & .021 & $-.069-.114$ & .016 & & -.001 & $-. .113-.117$ & .000 & & .009 & $-.112-.134$ & .005 & & .025 & $-.108-.168$ & .013 \\
\hline Religious & & -.117 & $-. .183--.054$ & -.084 & & .192 & $.107-.276$ & \begin{tabular}{|l|}
.103 \\
\end{tabular} & & .105 & $.014-.195$ & .055 & & -.039 & $-.133-.055$ & -.019 \\
\hline Inattention & & .057 & $-.011-.121$ & .060 & & -.159 & $-. .247--.072$ & -.126 & & -.092 & $-.189-.003$ & -.072 & & .142 & $.050-.237$ & .101 \\
\hline Hyperactivity & & .090 & $.021-.156$ & .094 & & -.101 & \begin{tabular}{|c|}
$-.190--.014$ \\
\end{tabular} & \begin{tabular}{|l|}
-.080 \\
\end{tabular} & & -.137 & $-.235--.037$ & -.106 & & .287 & $.192-.382$ & .203 \\
\hline
\end{tabular}

Note: $\mathrm{ADHD}=$ attention deficit/hyperactive disorder, $\mathrm{ASRS}=$ the Hebrew version of the Adult ADHD Self-Report Scale, Cost $=$ the perceived costs of adherence to preventive measures, Decrease in income $=$ decrease in income since the onset of the outbreak, Efficacy $=$ the perceived efficacy of the preventive measures, Norm $=$ the perceived norms regarding adherence to preventive measures, Psychological Distress $=$ Kessler Screening Scale for Psychological Distress (K6) score. Risk $=$ perceived risk of COVID-19, * $p<.001$. 